\title{
The role of shear stress in the pathogenesis of atherosclerosis
}

\author{
Kristopher S Cunningham ${ }^{1,2}$ and Avrum I Gotlieb ${ }^{1,2}$ \\ ${ }^{1}$ Department of Pathology, Toronto General Research Institute, University Health Network, Canada and \\ ${ }^{2}$ Department of Laboratory Medicine and Pathobiology, University of Toronto, Toronto, Ontario, Canada
}

\begin{abstract}
Although the pathobiology of atherosclerosis is a complex multifactorial process, blood flow-induced shear stress has emerged as an essential feature of atherogenesis. This fluid drag force acting on the vessel wall is mechanotransduced into a biochemical signal that results in changes in vascular behavior. Maintenance of a physiologic, laminar shear stress is known to be crucial for normal vascular functioning, which includes the regulation of vascular caliber as well as inhibition of proliferation, thrombosis and inflammation of the vessel wall. Thus, shear stress is atheroprotective. It is also recognized that disturbed or oscillatory flows near arterial bifurcations, branch ostia and curvatures are associated with atheroma formation. Additionally, vascular endothelium has been shown to have different behavioral responses to altered flow patterns both at the molecular and cellular levels and these reactions are proposed to promote atherosclerosis in synergy with other well-defined systemic risk factors. Nonlaminar flow promotes changes to endothelial gene expression, cytoskeletal arrangement, wound repair, leukocyte adhesion as well as to the vasoreactive, oxidative and inflammatory states of the artery wall. Disturbed shear stress also influences the site selectivity of atherosclerotic plaque formation as well as its associated vessel wall remodeling, which can affect plaque vulnerability, stent restenosis and smooth muscle cell intimal hyperplasia in venous bypass grafts. Thus, shear stress is critically important in regulating the atheroprotective, normal physiology as well as the pathobiology and dysfunction of the vessel wall through complex molecular mechanisms that promote atherogenesis.

Laboratory Investigation (2005) 85, 9-23, advance online publication, 29 November 2004; doi:10.1038/labinvest.3700215
\end{abstract}

Keywords: shear stress; atherosclerosis; endothelium; smooth muscle cells; nitric oxide; cytoskeleton; mechanotransduction

The parallel frictional drag force of shear stress is one of the important blood flow-induced mechanical stresses acting on the vessel wall, which also includes the perpendicular force of blood pressure and the cyclic stretch of pulsatile flow. Shear stress is a biomechanical force that is determined by blood flow, vessel geometry and fluid viscosity that is computationally estimated using fluid dynamics models and is expressed in units of dynes $/ \mathrm{cm}^{2}{ }^{1}$ Shear stress forces are imposed directly on the endothelium and modulate endothelial structure and function through the activities of local mechanotransduction mechanisms with the ultimate activation of shear stress response promoter elements/ transcription factors, that modulate endothelial gene expression. Several molecules, structures and processes have been implicated in mechanotransduc-

Correspondence: Dr AI Gotlieb, MDCM, FRCPC, Department of Laboratory Medicine and Pathobiology, Banting Institute, 100 College Street, Room 110, Toronto, Ontario, Canada M5R 1L5.

E-mail: avrum.gotlieb@utoronto.ca

Received and revised 20 October 2004; accepted 21 October 2004; published online 29 November 2004 tion of shear stress into specific biochemical signals and/or activated intracellular signaling pathways, resulting in modulation of cellular structure and function. The precise molecular mechanisms remain unknown; however, much new knowledge has been published to begin to understand how the cell senses shear stress, what signaling pathways are regulated by these molecular sensors and which genes are regulated by the downstream elements of these pathways. Indeed, due to normal laminar flow, shear stress is a critical factor in maintaining normal physiologic vascular function including thromboresistance, barrier function and vascular homeostasis. However, the pathogenesis of atherosclerosis is a complex multifactorial process of vascular wall injury and atheroma formation due to dynamic local and systemic factors ${ }^{2}$ (Figure 1). Shear stress, especially when blood flow is disturbed and/or is nonlaminar, plays an important role in the pathogenesis of the atherosclerotic plaque, especially where flow conditions are disturbed with low or oscillatory shear stress. The combination of altered arterial hemodynamics around curvatures, arterial branch ostia and bifurcations, ${ }^{1}$ where secondary 

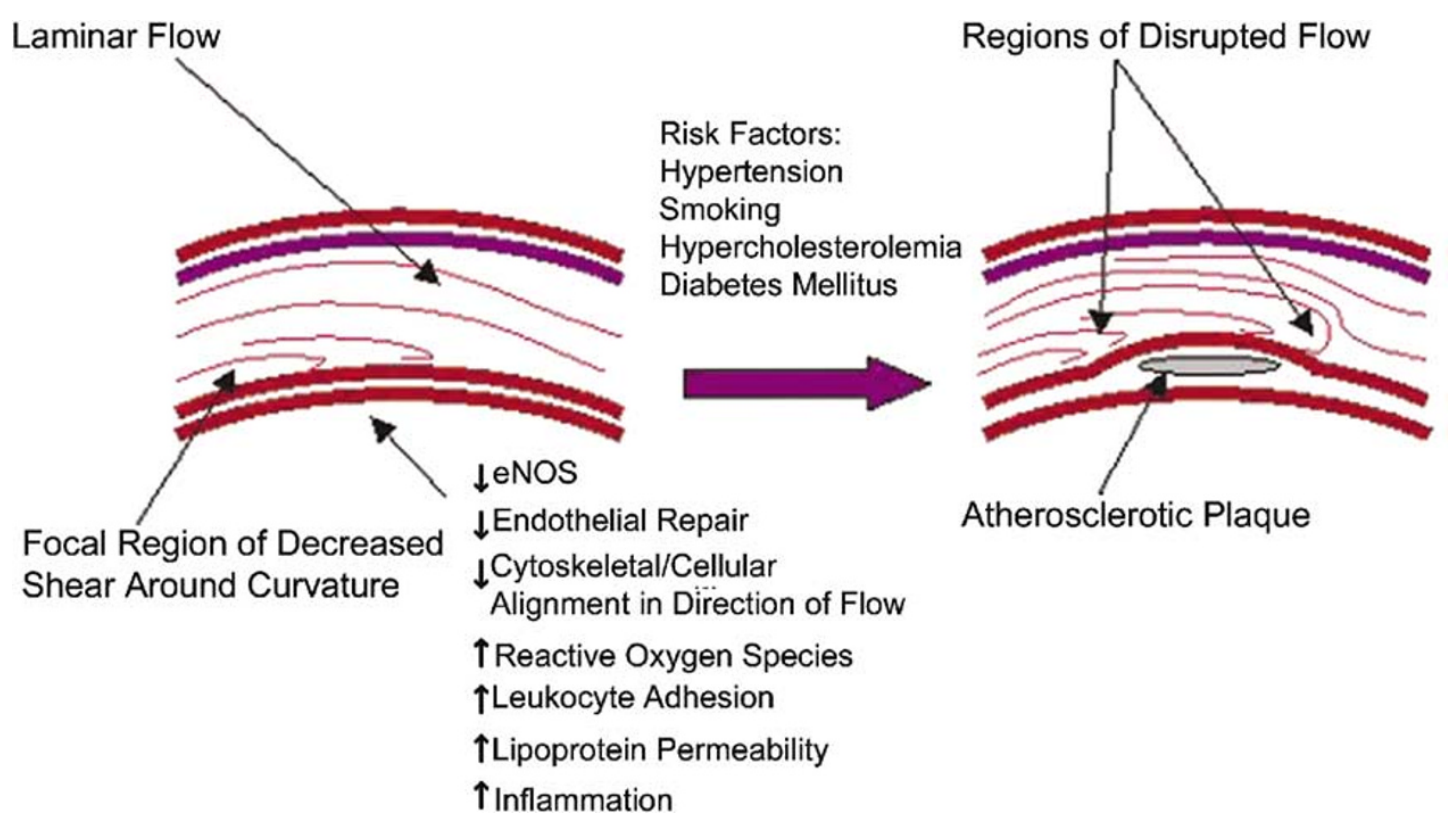

Figure 1 A model of atherogenesis at sites of decreased hemodynamic shear stress. Note that the decreased shear stress affects cellular morphology and numerous cell functions, several of which are atherogenic. In the presence of systemic risk factors, some of which are listed, there is an increased likelihood of atherosclerotic plaque formation at these sites, which once formed, further disrupts flow and promotes growth of the fibroinflammatory lipid plaque.

flows occur, and systemic risk factors promote atherosclerotic lesion initiation, progression and ultimately, development of complicated plaques. For example, atherogenesis is promoted by decreased shear stress $\left(<5\right.$ dynes $\left./ \mathrm{cm}^{2}\right)$ because it is associated with reduction in several vascular wall functions including endothelial nitric oxide synthase (eNOS) production, vasodilatation and endothelial cell repair. These are coupled with increases in reactive oxygen species (ROS), endothelial permeability to lipoproteins, leukocyte adhesion, apoptosis, smooth muscle cell proliferation and collagen deposition. ${ }^{3}$ In addition, many risk factors linked to cardiovascular disease such as hypertension, smoking, hyperlipidemia, hyperhomocysteinemia and diabetes mellitus have a direct impact on endothelial cell function ${ }^{4}$ and impair flow-mediated vasodilatation in a progressive and additive fashion. ${ }^{5}$ This is significant because endothelial-dependent vasomotion has been identified as an independent predictor of cardiac events. ${ }^{6}$ Fluid shear stress does play an important role in blood vessel formation, especially in angiogenesis, arteriogenesis and in aneurysm formation. These topics are beyond the scope of this review.

\section{Vascular shear stress}

Shear stress is expressed in the case of laminar flow where the profile of blood velocity is parabolic as

$$
\tau=4 \mu Q / \pi r^{3}
$$

where $\mu$ is the viscosity, $Q$ is the flow rate and $r$ is the vessel radius. Vascular shear stress of large conduit arteries typically varies between 5 and 20 dynes $/ \mathrm{cm}^{2}$; however, significant instantaneous values range from negative measures to nearly 40 dynes $/ \mathrm{cm}^{2}$ during states of increased cardiac output. ${ }^{1}$ This continuous exposure to a physiologic range of shear stress, especially in straight sections of the artery exposed to unidirectional laminar flow, promotes the establishment of important physiologic characteristics of the artery wall promoting an anti-inflammatory, antithrombotic, anticoagulative, profibrinolytic and antihypertrophic state. Shear is also integrally involved in flow-mediated vasodilatation as a means to normalize mechanical forces and thus helps to maintain normal endothelial function. Flow conditions in the artery are specified by the Reynolds number (Re), which is a measure of the stability of flow:

$$
\operatorname{Re}=4 \rho Q / \pi \mu D\left(\mathrm{~g} / \mathrm{cm}^{3}\right)
$$

where $\rho$ is the density of blood, $D$ is the vessel diameter, $\mu$ is the blood viscosity and $Q$ is the flow rate. This represents a ratio of inertial fluid momentum to viscous frictional forces. Thus, at very low flow rates, Re below $1 \mathrm{~g} / \mathrm{cm}^{3}$, viscous forces dominate over inertial forces and flow follows the geometry of flow channels. Secondary flows (vortices and other nonaxial flow phenomena) arise at greater Re when viscous forces and inertial forces are comparable. Secondary flows develop at arterial bends and bifurcations. Transition to turbulence, where lateral motion of the blood becomes fully randomized, occurs at $R e$ of 500 to $1500 \mathrm{~g} / \mathrm{cm}^{3}$ and is dependent on vascular geometries, the presence or absence of lumen stenosis and on flow pulsatility. ${ }^{7}$ 
Transient turbulence has been shown to occur in the human aorta at peak systole, during heavy dynamic exercise in much of the central arterial system and distal to arterial lumenal stenosis and aneurysms.

Thus, the endothelium is exposed to diverse flow patterns: laminar flow, which is the steady tangential drag force noted above; oscillatory flow, where time-averaged fluctuations in shear stress are very low or zero due to forward-reverse flow cycles and disrupted flows, which exhibit regions of flow separation, recirculation and reattachment that are associated with temporal and spatial shear gradients. ${ }^{1}$ Vascular smooth muscle cells (SMC) are also directly or indirectly responsive to shear stress resulting in regulation of cell proliferation, migration and differentiation between contractile and secretory phenotypes. ${ }^{8}$ The vascular wall is continuously fine-tuning its activities in response to vascular shear stress. However, significant changes and/or disruption of laminar flow impart changes in endothelial cell behavior, which alters the biology of the endothelial monolayer and subsequently the susceptibility of conduit vessels to atherosclerotic disease.

In studies by Brad Berk's group on how vascular remodeling maintains vessel lumen diameter and shear stress, they found that shear stress is differentially regulated among several inbred rat strains. This suggested that genetic determinants were important in regulating shear stress in response to changes in blood flow. ${ }^{9}$ Linder's group and Berk's group have also carried out vascular remodeling experiments, which support the notion that in mice vascular remodeling is strain dependent. ${ }^{10,11}$

\section{Endothelial and vascular SMC interactions}

Activated, proliferating vascular SMC play an essential role during atherogenesis. These cells contribute to intimal hyperplasia that forms the bulk of the plaque, to expression of growth factors, cytokines, and proinflammatory mediators such as monocyte chemoattractant protein-1 (MCP-1) and vascular cell adhesion molecule (VCAM) and to synthesis of matrix molecules some of which are important for retaining lipoproteins. ${ }^{12}$ Much of the endothelial-smooth muscle communication is through paracrine pathways; the best studied being nitric oxide (NO) regulation of vasodilatation. Although the internal elastic lamina separates medial vascular SMC from the abluminal endothelium, numerous membrane pores $(2-7 \mu \mathrm{m})$ permit direct communication between the endothelial cells and vascular SMC, potentially through myoepithelial bridges.. ${ }^{13,14}$ Interactions between these cell types are important for proper vessel wall function and both have been shown to be responsive to shear stress. For example, laminar shear stress inhibits not only endothelial but also vascular SMC prolifera- tion. ${ }^{15,16}$ Chiu et $a l^{17}$ demonstrated that in a modified coculture system exposed to the physiologic 12-dynes $/ \mathrm{cm}^{2}$ fluid flow, vascular SMC tended to orient themselves perpendicular to the direction of flow in contrast to endothelial cells, which are known to orient themselves parallel to flow. Also, shear stress less than 2 dynes $/ \mathrm{cm}^{2}$ had no effect on vascular SMC orientation. Importantly, coculture under static conditions induced leukocyte adhesion proteins GRO- $\alpha$ and MCP-1 expression while application of shear stress attenuated this response. This observation suggests that shear stress acts through the endothelium to modulate SMC gene expression imparting an atheroprotective phenotype on the vessel wall. The uptake of acylated-low-density lipoproteins (Ac-LDL) is decreased in endothelialSMC cocultures exposed to laminar shear stress relative to static cultures. Interestingly, shear stress increased uptake of unaltered LDL, suggesting that uptake of oxidized LDL is favored under low flow conditions, ${ }^{18}$ similar to that seen at those sites predicted at risk of atheroma formation. Nonuniform shear stress has been shown to influence the in vivo density of SMC in the vessel wall through a graded suppression of mitogenic activity at higher shear levels. The level of shear stress was inversely correlated with intimal SMC density, whereas exposure to laminar flow did not influence cell density. ${ }^{19}$ Altogether, these studies uphold the premise that shear stress acts on vascular SMC in part through endothelial interactions to modulate SMC gene expression, uptake of atherogenic lipoproteins and proliferation as a means of suppressing atheroma formation.

\section{Mechanotransduction of shear stress}

There appears to be several possible mechanisms by which endothelial cells sense stress and act as a shear transducer including those mediated by gene expression and those not mediated by gene expression. Following the initial mechanosensing, cell surfaces and cell membranes may be deformed, ions may be translocated, local biochemical responses may be activated, downstream intracellular signaling pathways may be activated and endothelial genes may then be expressed, all to modulate shear-induced endothelial function as well as important shear-induced alterations in endothelial cell morphology (Figure 2).

An early response to shear stress is the influx of $\mathrm{Ca}^{2+}$ leading to increased cytosolic $\mathrm{Ca}^{2+}$, which may lead to numerous changes in intracellular activation of molecules and production of bioactive agents such as NO. ${ }^{11}$ The membrane potential modulates the driving force for $\mathrm{Ca}^{2+}$ transmembrane fluxes since endothelial cells lack voltage-dependent $\mathrm{Ca}^{2+}$ channels. Ion channels that are mechanosensitive have been identified and characterized. ${ }^{20}$ Laminar shear stress promotes upregulation of IKca1 
SHEAR STRESS IN ATHEROGENESIS

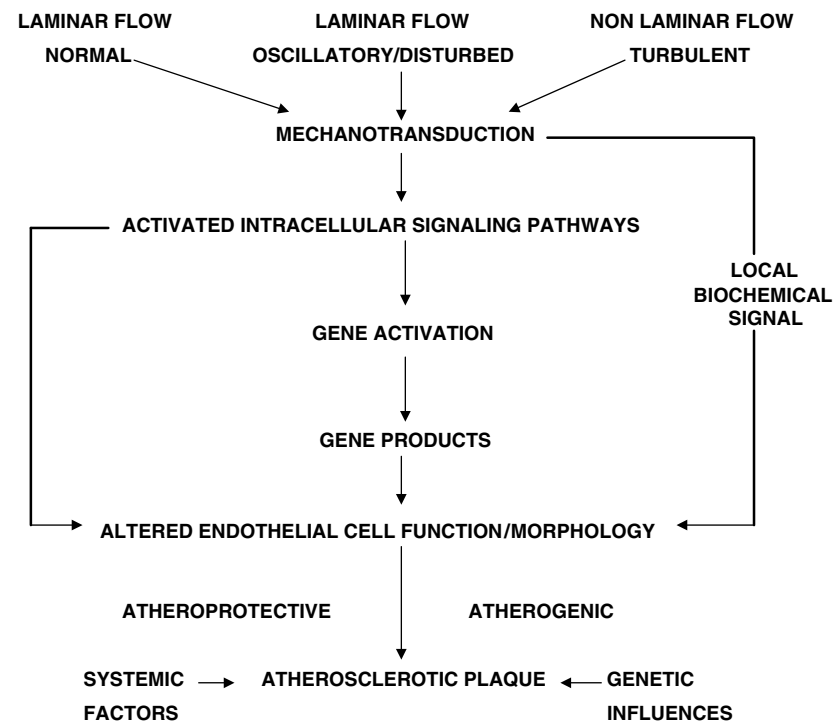

Figure 2 A schematic diagram of the pathways by which shear stress may regulate atherogenesis. The pathogenesis of the atherosclerotic plaque is modulated by shear stress regulation of atheroprotective and atherogenic influences, by systemic risk factors and by genetic influences that affect both multiple cellular processes in the wall and the plaque as well as the response of the vessel wall to shear stress itself.

transcription, resulting in increased intermediateconductance $\mathrm{Ca}^{2+}$-activated $\mathrm{K}^{+}$channel $\left(\mathrm{IK}_{\mathrm{Ca}}\right)$ activity, which results in hyperpolarization, and membrane-driven $\mathrm{Ca}^{2+}$ influx, which may be atheroprotective because of a likely increased synthesis of vasodilator and antithrombotic factors. ${ }^{21}$ Flow-activated ion currents including the hyperpolarizing current carried by inward rectifying $\mathrm{K}^{+}$channels and a depolarizing current due in part to outward rectifying Cl-channels show different sensitivities to high and to low shear stress and to oscillatory shear stress. $^{22}$ The endothelial cytoskeleton is also proposed to play a central role in the mechanotransduction of shear stress with direct participation of each of the three main structural cytoskeletal fibers as well as indirect involvement of cytoskeletalassociated structures such as focal adhesions and adherens junctions. ${ }^{23-25}$ Conformational changes in the cell cytoskeleton in response to shear forces may promote mechanotransduction, as may conformational changes in the cell-cell and the cell-substratum adhesion complexes. At the substratum, integrin-matrix interactions are also implicated in transduction primarily by activation of downstream pathways that are implicated in both anti- and pro-atherogenic activities. ${ }^{26}$ The glycocalyx ${ }^{27}$ is postulated to be disrupted by shear stress leading to modifications of ion channels and membrane receptors. Other factors and structures have been studied including dystrophin, ${ }^{28}$ caveolae, ${ }^{29}$ PECAM$1,{ }^{30}$ gap junctions ${ }^{31}$ as well as many other ancillary structural and signaling proteins. Rapid, shearinduced activation of Ras, a small G protein, ${ }^{32}$ may lead to activation of mitogenic signaling pathways through extracellular signal-regulated kinase (ERK) and Jun kinase (JNK). Exposure of endothelial cells to shear stress results in NO due to the dissociation of eNOS from caveolin- $1 .^{32}$ Chronic laminar shear stress induces translocation of caveolin-1 from the Golgi to the plasma membrane, increases caveolin formation at the lumenal side and changes ERK and Akt activation, reducing the former and enhancing the latter. ${ }^{33}$ Resnick et $a l^{1}$ reviewed the data that suggest that induction of laminar shear stress results in three patterns of gene expression immediate followed by decrease to static levels less immediate maintaining the altered levels of expression for several hours and delayed induction several hours after onset of shear stress. However, it is still unknown how shear stress ultimately results in the numerous transcriptional changes mediated by shear stress responsive promoter elements (SSREs) that bind transcription factors, which are also activated by shear stress. It must be noted that the exact mechanisms of converting a mechanical stress into a biochemical signal is thus not well understood and requires further study. The hope is that both shear stress receptors and shear stress responsive genes will be useful as biomarkers of atherosclerotic disease and as targets for therapies of atherosclerosis.

\section{Vascular biologic activity regulated by shear stress}

Expression patterns of many endothelial gene products that are recognized as being up- or downregulated in response to laminar and/or disturbed flows have been examined either in individual candidate gene studies or in large DNA array-based genomic analyses. ${ }^{34,35} \mathrm{~A}$ subset of these shear regulated factors are secreted by endothelial cells and may be grouped into functional classes that include vasoactive compounds, growth factors, coagulation/fibrinolysis/complement factors and extracellular matrix (ECM)/ECM modifying factors (Table 1). ${ }^{36-56}$ That many of these secreted products fall into functional classes should not be surprising as disturbed shear stress is likely to alter endothelial cell biology in a directed fashion, as a means to adapt to the new environmental conditions. Although for some gene products such as NO and tumor growth factor $\beta$ (TGF $\beta$ ), the response to shear stress is apparent, for others, such as plateletderived growth factor (PDGF), basic fibroblast growth factor (bFGF) and angiotensin converting enzyme (ACE), the impact of shear stress is less clear. ${ }^{57}$ The majority of studies on candidate genes and their products that were found to be responsive to shear were performed using in vitro endothelial monolayers exposed to various flow conditions in 
Table 1 Atherogenic/atheroprotective factors modulated by shear stress

\begin{tabular}{|c|c|}
\hline & References \\
\hline \multicolumn{2}{|l|}{ Vasoactive compounds } \\
\hline Angiotensin converting enzyme (ACE) & 36 \\
\hline NO-endothelial nitric oxide synthase (eNOS) & 37 \\
\hline NO-induced nitric oxide synthase (iNOS) & 38 \\
\hline Prostacyclin & 39 \\
\hline C-type natriuretic peptide & 40 \\
\hline Adrenomedullin & 41 \\
\hline Endothelin-1 & 42 \\
\hline \multicolumn{2}{|l|}{ Growth factors } \\
\hline Platelet-derived growth factor B (PDGFB) & 43 \\
\hline Epidermal growth factor (EGF) & 44 \\
\hline basic Fibroblast Growth Factor (bFGF) & 45 \\
\hline $\begin{array}{l}\text { Melanoma growth-stimulatory activity/ } \\
\text { growth-regulated gene-chemokine (GRO) }\end{array}$ & 46 \\
\hline $\begin{array}{l}\text { Granulocyte monocyte-colony stimulating } \\
\text { factor (GM-CSF) }\end{array}$ & 47 \\
\hline $\begin{array}{l}\text { Insulin-like growth factor binding protein } \\
\text { (IGFBP) }\end{array}$ & 55 \\
\hline \multicolumn{2}{|l|}{ Coagulation/fibrinolysis/complement } \\
\hline Thrombomodulin & 48 \\
\hline Tissue factor & 49 \\
\hline tissue Plasminogen Activator (tPA) & 50 \\
\hline $\begin{array}{l}\text { Protease-activated receptor-1-thrombin } \\
\text { receptor (PAR-1) }\end{array}$ & 51 \\
\hline Properdin—complement factor & 52 \\
\hline \multicolumn{2}{|l|}{ ECM/ECM degradation enzymes } \\
\hline Collagen XII & 53 \\
\hline Matrix metaloprotease-9 (MMP-9) & 54 \\
\hline \multicolumn{2}{|l|}{ Inflammation } \\
\hline Monocyte chemoattractant protein (MCP-1) & 69 \\
\hline Vascular cell adhesion molecule (VCAM-1) & 68 \\
\hline Intercellular adhesion molecule (ICAM-1) & 67 \\
\hline E-selectin & 70 \\
\hline Bone morphogenic protein (BMP-4) & 75 \\
\hline \multicolumn{2}{|l|}{ Others } \\
\hline Extracellular superoxide dismutase (ecSOD) & 117 \\
\hline $\begin{array}{l}\text { Sterol regulatory element binding protein } \\
\text { (SREBP) }\end{array}$ & 170 \\
\hline $\begin{array}{l}\text { Platelet/endothelial cell adhesion molecule } \\
\text { (PECAM-1) }\end{array}$ & 29 \\
\hline
\end{tabular}

milieus quite different from the in vivo vessel. An example of enhancing in vitro experimental models is the work of Michael Gimbrone's group who designed an in vitro dynamic flow system to reproduce arterial shear stress waveforms applied on cultured endothelial cells. They used 3D flow analysis based on actual aortic artery bifurcation geometries and blood flow profiles to characterize an athero-prone and an atheroprotective waveform, which were applied to the endothelial cells in culture to analyze gene expression using transcription profiling. ${ }^{58}$ Studies of gene expression in vivo, under conditions of either uniform or disrupted flow, have appeared ${ }^{35,59}$ confirming some but not all of the large body of in vitro data and shedding further light on potentially significant changes in factor production in regions at risk for developing in vivo atheromatous lesions.

Investigators in the field are cautious since gene expression profiles differ among different studies; however, among classes of genes there are similarities in global gene expression. For example, laminar shear stress promotes expression of antiinflammatory, antiproliferative, antiapoptotic and antioxidative genes. There are differences in the findings between various in vitro studies, which may reflect different models, use of cells from different species or derived from different locations, and different experimental design and sampling times. These differences have not yet been pursued with any rigor. In addition, flow preconditioning of cultured endothelial cells is considered important since these cells will change their phenotype, at least to some extent, adopting phenotypes that may not completely reflect those of in vivo endothelial cells. Thus, designing experiments that allow for the establishment of a hemodynamic environment prior to studying how alterations in shear stress alter cell morphology and function is a very useful experimental strategy.

\section{Inflammation}

Shear stress plays an important role in regulating the inflammatory processes that initiate and enhance the growth of the fibroinflammatory lipid plaque. Shear stress appears to heavily influence vascular inflammation through modification of endothelial gene expression to a proatherogenic profile. Many groups have utilized microarray analyses of endothelium under conditions of laminar vs disturbed shear stress to suggest that nonlaminar flow can result in gene expression of proinflammatory molecules in the vascular wall. ${ }^{60-62}$ Indeed, recent work has shown that both shear stress and cyclic strain in combination may better predict sites of proatherogenic gene expression. ${ }^{63}$ Analysis of vascular regions prone to atherogenesis due to disturbed blood flow in vivo have revealed that altered shear stress can prime the endothelium to respond to proatherogenic stimuli through upregulation of the proinflammatory transcription factor NF- $\kappa \mathrm{B} .{ }^{35,59}$ Laminar shear stress promotes an antiinflammatory and antioxidative expression profile, acting through promoter elements identified as SSREs, ${ }^{60}$ antioxidant response elements (ARE) ${ }^{64}$ and PPAR $\gamma$-response elements. ${ }^{65}$ Shear stress also induces phosphorylation of Ser-727 of the transcription factor STAT3 via the ERK 1/2 pathway, which inhibits Tyr-705 phosphorylation in STAT3. This results in a reduced translocation of STAT3 into the nucleus and this attenuation of STAT3 activation reduces inflammatory responses through reduced cytokine stimulation. ${ }^{66}$ However, the interaction between shear stress and inflammation appears to be more complex given that laminar shear stress can also modulate 
proinflammatory cytokine ( $\mathrm{TNF} \alpha$ )-dependent transcription in endothelial cells. ${ }^{67}$ Thus, a fine balance exists between the expression of atheroprotective and proatherogenic genes mediated by levels of laminar shear stress and decreased shear, respectively.

Low shear stress influences adhesion of leukocytes to activated endothelium through enhanced expression of adhesion molecules such as ICAM- $1,{ }^{67}$ VCAM-1, ${ }^{68}$ MCP-1 ${ }^{69}$ and E-selectin. ${ }^{70}$ In addition, laminar flows have been found to antagonize the ability of the proinflammatory cytokine, $\mathrm{TNF} \alpha$, to recruit leukocytes and induce expression of vascular endothelial growth factor (VEGF)-1 and E-selectin, ${ }^{67,71}$ reinforcing the balance sought between the pro- and anti-inflammatory influences of oscillatory and laminar shear stress, respectively. Mediation of this antagonism may involve inhibition of MAP kinase activation (eg JNK) as well as association of TRAF-2 with TNFR- $1{ }^{72}$ Interestingly, laminar shear stress also inhibited vascular SMC-dependent promotion of endothelial adhesion molecule expression in coculture under static conditions, a process requiring close communication between the two cell types. ${ }^{73}$ Bone morphogenic protein- 4 (BMP-4), a member of the TGF $\beta$ family of cytokines, has recently been shown to be upregulated in endothelium over lipid-filled atheroma as well as in those cells exposed to oscillatory shear stress. ${ }^{74}$ Elevated levels of BMP-4 were also correlated with increased ICAM-1 expression through an NF- $\kappa \mathrm{B}$-dependent mechanism. It is worth noting that BMP-4 was previously identified in calcified atherosclerotic plaques $^{75}$ and calcific heart valves ${ }^{76}$ however, its specific role in shear-stress-dependent leukocyte adhesion is unknown.

\section{Nitric oxide}

NO is a central mediator in vascular biology and physiologic flow is the primary stimulus for continuous NO production by the endothelium. ${ }^{77} \mathrm{NO}$ synthase (NOS) catalyzes the NADPH-dependent conversion of L-arginine and $\mathrm{O}_{2}$ to L-citrulline and the short-lived radical NO. One of the primary functions of NO involves the regulation of vascular caliber to modulate blood flow and normalize endothelial shear stress and cyclic strain. ${ }^{78}$ The molecular mechanisms of NO activity include roles in signaling, free radical scavenging and posttranslational protein modification through $S$-nitosylation. ${ }^{79} \mathrm{NO}$ is atheroprotective through enhanced vascular relaxation as well as through inhibition of platelet activation and aggregation, apoptosis and endothelial-dependent monocyte adhesion. ${ }^{80-82}$ However, NO is not necessary to suppress endothelial activation chronically; rather it counterbalances factors that arise, which promote proatherogenic changes in endothelial cell behavior. ${ }^{83}$ Attenuation of NO is one of the earliest biochemical changes preceding endothelial dysfunction, which is an important concept highlighted by a recent metaanalysis showing that common genetic variations in the eNOS gene, and presumably NO availability, is an important risk factor in atherosclerosis and ischemic heart disease. ${ }^{84}$

Endothelial NOS is regulated by biomechanical stimuli and multiple biochemical factors, including acetylcholine, ${ }^{85} \quad \mathrm{H}_{2} \mathrm{O}_{2},{ }^{86}$ estrogen, ${ }^{87}$ bradykinin, ${ }^{88}$ sphingosine-1-phosphate ${ }^{89} \mathrm{VEGF},{ }^{90} \mathrm{TNF} \alpha,{ }^{91}$ as well as shear stress and flow-related aerobic exercise. ${ }^{92}$ In diseased vessels, the endothelium overlying atherosclerotic plaques shows a decrease in eNOS mRNA and protein expression, ${ }^{93}$ which correlates well with plaques occurring and growing in regions of disturbed blood flow where there is impaired endothelial-dependent vasorelaxation..$^{93,94}$

The complexity of eNOS activity involves multiple levels of regulation, not the least of which is gene expression. NF- $\kappa \mathrm{B}$ is a transcription factor activated in regions of disturbed flow and is predicted to mediate proinflammatory gene expression in response to shear stress. ${ }^{35,59}$ This phenomenon is believed to be associated with a decrease in eNOS activity. Interestingly, Davis et $a l^{37}$ show that under conditions of laminar flow, NF- $\kappa \mathrm{B}$ binds to the eNOS promoter and transiently upregulates eNOS transcription, followed by a prolonged increase in the stability of eNOS mRNA. ${ }^{95}$ Given that NO inhibits NF- $\kappa$ B activation, ${ }^{96}$ it is suggested that laminar shear stress may provoke a negative feedback loop with shear stress inducing eNOS expression through NF- $\kappa \mathrm{B}$, which is followed by increased NO production and subsequent NO-dependent decreases in NF- $\kappa \mathrm{B}$ activity. Factors that interfere with NO activity, such as ROS, that are produced in regions of low shear stress, could potentially lead to unchecked elevations in NF- $\kappa \mathrm{B}$-dependent, proinflammatory gene expression. ${ }^{37}$

The mechanism of eNOS activation appears to involve its subcellular location, an association in multiprotein complexes, as well as targeted tyrosine phosphorylations. Endothelial NOS was shown to be associated with caveolae and is inhibited through its interaction with caveolin-1. ${ }^{97}$ Although eNOS has also been found to be associated with other subcellular structures such as the Golgi apparatus and the mitochondrion, the functional significance of these interactions is unclear. ${ }^{98}$ Multiple protein partners of eNOS have been identified in which some promote eNOS activity such as $\mathrm{Ca}^{2+} / \mathrm{CaM},{ }^{99}$ hsp90, ${ }^{100}$ dynamin-2, ${ }^{101}$ porin $^{102}$ and guanylate cyclase $^{103}$ and some suppress eNOS activity such as caveolin-1, ${ }^{97}$ G-protein coupled receptors, ${ }^{104}$ and NO-interacting protein (NOSIP). ${ }^{105}$ Recent evidence also demonstrates that eNOS interacts with and is inhibited by the transmembrane intercellular adhesion molecule, PECAM-1, a protein postulated to act in the mechanotransduction pathway. ${ }^{106}$ This interaction is disrupted over seconds in response to acute increases in shear stress and correlates with a parallel increase in eNOS activity. However, the 
interaction is not perturbed in response to shear stress with a low temporal gradient. Acute changes in shear stress are also associated with tyrosine phosphorylation of PECAM-1, ${ }^{107}$ an event required for the flow-dependent activation of ERK, ${ }^{30}$ a MAP kinase.

Production of eNOS as a result of shear is biphasic. Initially, there is a $\mathrm{Ca}^{2+} / \mathrm{CaM}$-dependent disruption of eNOS' interaction with caveolin-1, resulting in the production of NO secondary to acute changes in shear stress. Then there is a more $\mathrm{Ca}^{2+}$ independent, slow production of NO in response to steady laminar flows. ${ }^{99}$ The precise mechanism of steady NO production is not entirely clear, yet binding of Hsp90 to eNOS ${ }^{100}$ and protein kinase A (PKA)-dependent phosphorylation of eNOS 5635 (bovine sequence) appear to play a role. ${ }^{108}$ Targeted phosphorylation of eNOS on residues S1179, S635 and potentially S617 and S116 (bovine sequences) may also increase enzyme activity in response to shear stress. ${ }^{109}$ Additionally, it appears that dephosphorylation of T497 is required for optimal activation of eNOS; ${ }^{110}$ however, appropriate phosphorylation of T497 is argued to regulate production of NO as oppossed to superoxide anions from eNOS. ${ }^{111}$ Numerous kinases have been identified for each site, especially S1179, including PKA, ${ }^{112}$ Akt, ${ }^{113}$ PKG, ${ }^{114}$ AMP-activated protein kinase $(\mathrm{AMPK})^{110}$ and CaM-dependent kinase II (CaMKII). ${ }^{115}$ Laminar shear stress appears to act primarily through Akt and PKA. Supportive roles for the other enzymes have been suggested. ${ }^{109}$ A recent observation demonstrated that the catalytic subunit of PKA is associated with eNOS in luminal lamellipodia located near endothelial cell junctions in restricted intracellular locales, ${ }^{116}$ the existence of which may help to elucidate differential regulation of eNOS by PKA. Shear stress has been shown to activate the vascular endothelial growth factor II receptor (VEGFRII) in a ligand-independent manner, recruiting phosphoinositide 3-kinase $\left(\mathrm{PI}_{3} \mathrm{~K}\right)$ and subsequently activating Akt and eNOS. ${ }^{117}$ Interestingly, like PECAM-1, VEGFRII activation is associated with shear stress-dependent tyrosine phosphorylation, in this case known to be src-dependent, over the same time frame of PECAM-1 phosphorylation and eNOS release from caveolae and PECAM-1. However, whether any of these events are linked is still unknown. Exercise training has been shown to induce a shear-dependent increase in c-src activity associated with eNOS and extracellular superoxide dismutase activation. ${ }^{118}$ Related studies have also shown that shear stress induced by exercise induces enhanced S1179 phosphorylation ${ }^{119}$ and potentially recruites eNOS containing caveolae to the plasma membrane, ${ }^{29}$ possibly helping to explain the means by which regular exercise can be atheroprotective. Laminar shear stress has also been shown to increase the $S$-nitrosylation of proteins such as caspase-3 and thioredoxin, ${ }^{120}$ facilitating the antiapoptotic and antioxidative role of steady shear flows.
It is postulated that oscillatory shear stress, disrupted flows and turbulent flows act on the vascular wall to disrupt these atheroprotective molecular pathways reducing the production of NO and thus changing the biology of the vessel. This results in the production of proinflammatory mediators through NF- $\kappa \mathrm{B}$-dependent transcription, impaired flow regulated vasorelaxation and reversal of the antiapoptotic, antiproliferative (relevant to vascular SMC) and antioxidative (relevant to LDL) functions of the endothelium. Microparticles, which are membranous vesicles released from activated $\mathrm{T}$ lymphocytes with procoagulant and proinflammatory properties, induce endothelial dysfunction by decreasing eNOS expression and overexpressing caveolin-1 in endothelial cells activated during atherogenesis. $^{121}$ This observation serves to illustrate that once the atheroprotective role of the endothelium, in part through its eNOS activity, has been compromised, a vicious cycle of vascular wall injury inducing plaque formation and subsequent disruption in blood flow can facilitate atheroma progression and potentially impart vulnerability onto atherosclerotic lesions. An important recent study shows that a single nucleotide polymorphism of the human eNOS gene $\left({ }^{-786} \mathrm{C} / \mathrm{T}\right)$ renders affected patients at higher risk of coronary heart disease through a mechanism that is the result of an inability for shear stress to maintain basal levels of eNOS expression. ${ }^{122}$

\section{Reactive oxygen species}

The association between ROS production and atheroma formation is well established and involves shear stress. ROS production occurs in many cell types in the vascular wall such as endothelial cells, vascular SMC, adventitial fibroblasts and macrophages. ${ }^{123}$ There are at least five different enzyme systems contributing to the oxidation state of the vascular wall. These include lysyl oxidase (LOX), responsible for the covalent cross-linking of collagen and elastin, ${ }^{124}$ xanthene oxidase (XO), ${ }^{125}$ monocytederived ROS, ${ }^{126}$ uncoupled $\mathrm{eNOS}^{127}$ and the $\mathrm{NAD}(\mathrm{P}) \mathrm{H}$ family of oxidases, which are the primary contributors of ROS species in the vasculature. ${ }^{128}$ ROS increase leukocyte adhesion molecule expression, ${ }^{129}$ stimulate SMC proliferation and migration, promote lipid oxidation, upregulate matrix metaloproteinase activity and alter vasomotor activity. ${ }^{130}$

Shear stress modulates the redox state of the vascular wall, in part, by regulating expression of the different oxidase systems involved. The $\mathrm{NAD}(\mathrm{P}) \mathrm{H}$ family of oxidases are structurally different from the well-known phagocytic NAD(P)H oxidases and can be regulated by angiotensin II, through a phospholipase D-dependent process, ${ }^{131}$ inflammatory cytokines and shear stress. ${ }^{132}$ Endothelial cells exposed to oscillatory shear stress show a marked increase in $\mathrm{NAD}(\mathrm{P}) \mathrm{H}$ activity and ROS production in contrast to the antioxidative state 
induced by laminar flow. ${ }^{132}$ It has been proposed that XO expression may be regulated by NAD(P)H oxidase activity and that $\mathrm{XO}$ is actually the primary source of ROS in the vascular wall in response to oscillatory shear stress. ${ }^{125}$ Chronic exposure of endothelial cells to oscillatory shear stress increased monocyte adhesion, which is dependent on NAD(P)H oxidase activity. ${ }^{129}$ Finally, it was recently demonstrated that vascular $\mathrm{NAD}(\mathrm{P}) \mathrm{H}$ oxidase subunit, NOX4, expression increased in response to oscillatory shear stress and was associated with an increase in LDL oxidation relative to that in static cultures. ${ }^{133}$

XO, expressed by endothelium binds extracellular glycosaminoglycans and was found to be higher in individuals with coronary artery disease compared with normal controls. ${ }^{130}$ eNOS, although classically described as being atheroprotective, can significantly contribute to ROS production if electron transfer within the enzyme becomes uncoupled secondary to loss of either the cofactor 5,6,7, 8,-tetrahydrobiopterin $\left(\mathrm{BH}_{4}\right)$ or the substrate Larginine, resulting in the transfer of electrons to $\mathrm{O}_{2}$, forming superoxide. ${ }^{127}$ Interestingly, hypercholesterolemia, ${ }^{134}$ diabetes ${ }^{135}$ and hypertension ${ }^{136}$ have all been associated with eNOS uncoupling, potentially through ROS production, further potentiating the creation of superoxide.

In addition to the upregulation of oxidases, shear stress may promote changes in other antioxidative systems. Intracellular glutathione, providing reduction equivalents, is decreased under nonlaminar flows ${ }^{130,137}$ and the enzyme glutathione peroxidase is upregulated under laminar flow conditions. ${ }^{138}$ Of the three forms of the atheroprotective superoxide dismutase (SOD) found in the vascular wall, ${ }^{139}$ extracellular SOD and $\mathrm{Cu} / \mathrm{Zn}$ SOD may be stimulated by shear stress indirectly through enhanced eNOS production. ${ }^{140,141}$ Elevated levels of extracellular SOD have even been found in patients with acute coronary syndromes, potentially representing an important protective factor against oxidative stress associated with ischemic events. ${ }^{142}$ As stated above, adequate eNOS-dependent NO radical production allows ROS to be continually scavenged. Whether the vascular biology is impacted principally by loss of eNOS activity with an associated rise in ROS vs primarily negative effects associated with elevated ROS is unclear.

Systemic cardiovascular risk factors such as smoking, ${ }^{143}$ hypertension, ${ }^{144}$ diabetes $^{145}$ and hyperlipidemia, ${ }^{146}$ which are known to influence shear stress, are associated with elevated NAD(P)H oxidase activity and increased oxidative stress in the vessel wall. Importantly, angiotensin II receptor antagonists and ACE inhibitors have been shown to reduce $\mathrm{NAD}(\mathrm{P}) \mathrm{H}$ oxidase activity, ${ }^{147}$ suggesting a role for the renin-angiotensin system in promoting vascular oxidative stress. ${ }^{148}$ Statins also appear to reduce oxidative stress through suppression of $\mathrm{NAD}(\mathrm{P}) \mathrm{H}$ oxidase activity, independently of its role as an HMG-CoA reductase inhibitor. ${ }^{149}$ A role for antioxidants and L-arginine to modulate the proatherogenic effects of turbulent blood flow has been suggested using cell culture and murine models; ${ }^{150}$ however, successfully reducing vessel wall oxidative stress with antioxidants in human patient populations has not been as encouraging. ${ }^{151}$ Although work has focused on the role of oxidative stress in promoting atheroma formation, plaque evolution and vulnerability are also advanced by the redox state of the vasculature, potentially associated with angiogenesis and thus with intraplaque hemorrhage. ${ }^{152}$

\section{Vascular permeability}

Disturbed shear stress directly influences endothelial integrity and thus permeability due, in part, to modulation of cytoskeletal contractile function (see below). Regions prone to atherosclerosis have increased uptake by the arterial wall of fluorescent, radiolabeled and chromogenic tracers modeled to represent serum lipoprotein particles. ${ }^{153}$ Disturbed flow may increase particle transit times in susceptible regions ${ }^{154}$ and it has even been suggested that the proliferative effects of nonlaminar flows may enhance permeability during mitosis of endothelial cells. ${ }^{155}$ In the porcine proximal external iliac artery, a region known for complex blood flow, endothelial permeability to Evans blue dye tagged albumin decreased with increasing time-averaged shear stress in the physiologic range in contrast to the increased permeability observed under oscillatory shear conditions. ${ }^{156}$ However, enhanced retention of lipoprotein particles by the extracellular matrix and not increased transport per $s e^{25,154}$ may promote the site selectivity of atheroma formation.

\section{Cytoskeleton}

Shear stress has a profound effect on the endothelial cytoskeleton, ${ }^{25,157-159}$ especially the actin and the microtubule cytoskeletons, which are essential in maintaining the integrity of the vascular endothelium, and regulating endothelial repair following endothelial disruption and/or endothelial denudation due to cell loss. ${ }^{157-159}$ Actin microfilaments are arranged both centrally and peripherally in endothelial cells to form stress fibers ${ }^{160}$ and a dense peripheral band, ${ }^{161}$ respectively. Stress fibers are long bundles of actin filaments containing myosin, tropomyosin and alpha-actinin that can contract and exert tension. ${ }^{162}$ They are linked to the plasma membrane at focal adhesion sites where they serve to promote strong attachment to the substratum. ${ }^{24}$ The dense peripheral band, on the other hand, plays a role in cell-cell adhesion ${ }^{161,163,164}$ and likely acts, at least in part, to regulate endothelial permeability. Partial disassembly of the adherens junction complex is induced by shear stress and is followed by 
reassembly that is associated with endothelial shape change and reorganization of F-actin distribution. ${ }^{164}$ The distribution and organization of the actin cytoskeleton is altered in response to hemodynamic shear stress. For example, low hemodynamic shear favors prominent peripheral microfilaments, ${ }^{159}$ while elevated hemodynamic shear stress ${ }^{165}$ promotes an increase in central microfilaments. In cells exposed to high shear conditions, the central microfilaments become both thicker and longer, while the dense peripheral band becomes disrupted. These changes are reversible if normal shear is reinstated. ${ }^{165}$ Sustained exposure to flow also induces cytoskeletal remodeling that results in orientation of the endothelial cells in the direction of flow. ${ }^{166,167}$ Physiologic shear stress has been shown to be necessary for timely repair of the mechanically injured endothelium. ${ }^{159}$ Within in vivo mechanical injury models, low flow rates are associated with poor cell-cell contacts and disordered alignment of the cytoskeleton in cells along the wounded endothelium resulting in disturbed repair. ${ }^{159}$ Disturbed repair may not only promote atheroma formation through enhanced endothelial permeability but may also lead to the formation of endothelial erosions and fissures that are associated with complicated atherosclerotic lesions and rupture of unstable plaques. ${ }^{169}$ In a hypercholesterolemic rabbit model actin microfilaments undergo prominent changes, which initially may promote endothelial-substratum adhesion but eventually results in a reduction of stress fibers and dysfunctional adhesion. ${ }^{170}$ An interesting finding linking shear stress, actin microfilament system and cholesterol metabolism is that shear stress activates the Rho-ROCK-LIMK-cofilin pathway, which results in modulation of sterol regulatory element binding proteins (SREBPs) that regulate lipid and cholesterol metabolism. ${ }^{171}$

\section{Vein grafts and restenosis}

Shear stress has been implicated in affecting longterm vein graft patency, following coronary artery bypass procedures and vascular remodeling. Vein graft adaptations following introduction of arterial pressures involve elements of both intimal hyperplasia and expansive remodeling with local shear stress levels determining the balance between the two. Graft failure may be a consequence of enhanced neointimal hyperplasia secondary to vascular SMC proliferation from predominantly vein-derived cells. ${ }^{172}$ Interestingly, preferential fibromuscular hyperplasia of the vein intima at the distal anastomosis, ${ }^{173}$ which is likely secondary to disturbed flows, may have a secondary effect on the long-term flow velocity through the body of the graft, tipping the balance toward lower shear stresses and enhanced neointimal hyperplasia. Late restenosis following balloon angioplasty and stent placement is also associated with neointimal hyperplasia, which is inversely related to the shear stress distribution within the arterial segment, such that low shear stress regions are associated with maximal intimal thickness and high shear regions with minimal thickness. ${ }^{174}$ Numerous models have been proposed to explain the changes in shear stress. These include the creation of disturbed shear secondary to the significantly elevated flow velocities, ${ }^{175}$ prolonged inflammatory response to the stent promoting vascular SMC proliferation/migration $^{176}$ and the stent design itself modulating local shear gradients. ${ }^{177}$ It is intriguing to observe that intimal hyperplasia has also been shown to occur in regions of low shear stress proximally and distally to the stent itself, ${ }^{178}$ suggesting that the stent may indeed have more far-reaching influences on arterial architecture.

\section{Conclusions}

Shear stress is involved in both physiologic and pathophysiologic vascular biology. Modulation of vascular wall behavior in regions of disturbed blood flow in conjunction with the impact of systemic vascular factors such as smoking, hyperlipidemia, hyperglycemia and hypertension promotes a chronic fibroinflammatory response to the resultant arterial injury. This response is associated with a disarming of the atheroprotective defenses encouraged by laminar blood flow. The consequences of this dynamic interaction between shear stressinduced changes and systemic risk factors not only promotes atherosclerosis but also influences the success of those therapeutic modalities used to modify disease progression and clinical outcomes. A major challenge in the field is to integrate the large body of data on shear-dependent endothelial gene expression to identify useful biomarkers for atherosclerosis, to design appropriate approaches to prevent atherogenesis and to provide useful therapeutic interventions for atherosclerosis, especially complicated fibroinflammatory lipid plaques.

\section{References}

1 Resnick N, Yahav H, Shay-Salit A, et al. Fluid shear stress and the vascular endothelium: for better and for worse. Prog Biophys Mol Biol 2003;81:177-199.

2 Gotlieb AI, Silver MD. Cardiovascular Pathology, 3rd edn. Churchill-Livingstone: New York, NY, 2001.

3 Gimbrone MA, Topper JN, Nagel T, et al. Endothelial dysfunction, hemodynamic forces, and atherogenesis. Atherosclerosis V: the Fifth Saratoga Conference 2000;902:230-240.

4 Landmesser U, Hornig B, Drexler H. Endothelial function-a critical determinant in atherosclerosis? Circulation 2004;109:27-33.

5 Celermajer DS, Sorensen KE, Bull C, et al. Endothelium-dependent dilation in the systemic arteries of asymptomatic subjects relates to coronary risk-factors 
and their interaction. J Am Coll Cardiol 1994;24: 1468-1474.

6 Halcox JPJ, Schenke WH, Zalos G, et al. Prognostic value of coronary vascular endothelial dysfunction. Circulation 2002;106:653-658.

7 Nichols WW, O’Rourke MF. McDonald's Blood Flow in Arteries. Lea and Febiger: Philadelphia, 1990.

8 Wang L, Karlsson L, Moses S, et al. Specific P2 receptor profiles in human vascular smooth muscle cells and endothelial cells. Drug Dev Res 2002;56:569.

9 Ibrahim J, Miyashiro JK, Berk BC. Shear stress is differentially regulated among inbred rat strains. Circ Res 2003;92:1001-1009.

10 Korshunov VA, Berk BC. Strain-dependent vascular remodeling-The 'Glagov phenomenon' is genetically determined. Circulation 2004;110:220-226.

11 Harmon KJ, Couper LL, Lindner V. Strain-dependent vascular remodeling phenotypes in inbred mice. Am J Pathol 2000;156:1741-1748.

12 Dzau VJ, Braun-Dullaeus RC, Sedding DG. Vascular proliferation and atherosclerosis: new perspectives and therapeutic strategies. Nat Med 2002;8:12491256.

13 Campbell GJ, Eng P, Roach MR. Fenestrations in the internal elastic lamina at bifurcations of human cerebral-arteries. Stroke 1981;12:489-496.

14 Little TL, Xia J, Duling BR. Dye tracers define differential endothelial and smooth-muscle coupling patterns within the arteriolar wall. Circ Res 1995; 76:498-504.

15 Akimoto S, Mitsumata M, Sasaguri T, et al. Laminar shear stress inhibits vascular endothelial cell proliferation by inducing cyclin-dependent kinase inhibitor p21(Sdi1/Cip1/Waf1). Circ Res 2000;86:185-190.

16 Liu SQ. Focal expression of angiotensin II type 1 receptor and smooth muscle cell proliferation in the neointima of experimental vein grafts-relation to eddy blood flow. Arteriosclerosis Thrombosis Vasc Biol 1999;19:2630-2639.

17 Chiu JJ, Chen LJ, Chen CN, et al. A model for studying the effect of shear stress on interactions between vascular endothelial cells and smooth muscle cells. J Biomech 2004;37:531-539.

18 Niwa K, Kado T, Sakai J, et al. The effects of a shear flow on the uptake of LDL and acetylated LDL by an EC monoculture and an EC-SMC coculture. Ann Biomed Eng 2004;32:537-543.

19 Liu SQ, Tang DL, Tieche C, et al. Pattern formation of vascular smooth muscle cells subject to nonuniform fluid shear stress: mediation by gradient of cell density. Am J Physiol-Heart Circ Physiol 2003;285: H1072-H1080.

20 Nilius B, Droogmans G. Ion channels and their functional role in vascular endothelium. Physiol Rev 2001;81:1415-1459.

21 Brakemeier S, Kersten A, Eichler I, et al. Shear stress-induced up-regulation of the intermediateconductance $\mathrm{Ca}^{2+}$-activated $\mathrm{K}^{+}$channel in human endothelium. Cardiovasc Res 2003;60:488-496.

22 Lieu DK, Pappone PA, Barakat AI. Differential membrane potential and ion current responses to different types of shear stress in vascular endothelial cells. Am J Physiol-Cell Physiol 2004;286:C1367C1375

23 Mccue S, Noria S, Langille BL. Shear-induced reorganization of endothelial cell cytoskeleton and adhesion complexes. Trends Cardiovasc Med 2004; 14:143-151.

24 Davies PF, Robotewskyj A, Greim ML. Quantitative studies of endothelial cell adhesion. Directional remodeling of focal adhesion sites in response to flow forces. J Clin Invest 1994;93:2031-2038.

25 Helmke BP, Goldman RD, Davies PF. Rapid displacement of vimentin intermediate filaments in living endothelial cells exposed to flow. Circ Res 2000;86: $745-752$

26 Shyy JY, Chien S. Role of integrins in endothelial mechanosensing of shear stress. Circ Res 2002;91: 769-775.

27 Florian JA, Kosky JR, Ainslie K, et al. Heparan sulfate proteoglycan is a mechanosensor on endothelial cells. Circ Res 2003;93:E136-E142.

28 Loufrani L, Dubroca C, You D, et al. Absence of dystrophin in mice reduces NO-dependent vascular function and vascular density: total recovery after a treatment with the aminoglycoside gentamicin. Arteriosclerosis Thrombosis Vasc Biol 2004;24:671-676.

29 Rizzo V, Morton C, Depaola N, et al. Recruitment of endothelial caveolae into mechanotransduction pathways by flow conditioning in vitro. Am J PhysiolHeart Circ Physiol 2003;285:H1720-H1729.

30 Osawa M, Masuda M, Kusano K, et al. Evidence for a role of platelet endothelial cell adhesion molecule-1 in endothelial cell mechanosignal transduction: is it a mechanoresponsive molecule? J Cell Biol 2002; 158:773-785.

31 Cowan DB, Lye SJ, Langille BL. Regulation of vascular connexin43 gene expression by mechanical loads. Circ Res 1998;82:786-793.

32 Gudi S, Huvar I, White CR, et al. Rapid activation of Ras by fluid flow is mediated by $\mathrm{G}$ alpha(q) and $\mathrm{G}$ beta gamma subunits of heterotrimeric $G$ proteins in human endothelial cells. Arteriosclerosis Thrombosis Vasc Biol 2003;23:994-1000.

33 Boyd NL, Park H, Yi H, et al. Chronic shear induces caveolae formation and alters ERK and Akt responses in endothelial cells. Am J Physiol-Heart Circ Physiol 2003;285:H1113-H1122.

34 Brooks AR, Lelkes PI, Rubanyi GM. Gene expression profiling of human aortic endothelial cells exposed to disturbed flow and steady laminar flow. Physiol Genom 2002;9:27-41.

35 Passerini AG, Polacek DC, Shi CZ, et al. Coexisting proinflammatory and antioxidative endothelial transcription profiles in a disturbed flow region of the adult porcine aorta. Proc Natl Acad Sci USA 2004;101:2482-2487.

36 Rieder MJ, Carmona R, Krieger JE, et al. Suppression of angiotensin-converting enzyme expression and activity by shear stress. Circ Res 1997;80:312-319.

37 Davis ME, Grumbach IM, Fukai T, et al. Shear stress regulates endothelial nitric-oxide synthase promoter activity through nuclear factor kappa B binding. J Biol Chem 2004;279:163-168.

38 Ozawa N, Shichiri M, Iwashina M, et al. Laminar shear stress up-regulates inducible nitric oxide synthase in the endothelium. Hypertens Res 2004;27:93-99.

39 Frangos JA, Eskin SG, Mcintire LV, et al. Flow effects on prostacyclin production by cultured humanendothelial cells. Science 1985;227:1477-1479. 
40 Okahara K, Kambayashi J, Ohnishi T, et al. Shearstress induces expression of Cnp gene in human endothelial-cells. FEBS Lett 1995;373:108-110.

41 Chun TH, Itoh $\mathrm{H}$, Ogawa $\mathrm{Y}$, et al. Shear stress augments expression of C-type natriuretic peptide and adrenomedullin. Hypertension 1997;29:12961302.

42 Sharefkin JB, Diamond SL, Eskin SG, et al. Fluid-flow decreases preproendothelin messenger-RNA levels and suppresses endothelin-1 peptide release in cultured human endothelial-cells. J Vasc Surg 1991; 14:1-9.

43 Palumbo R, Gaetano C, Antonini A, et al. Different effects of high and low shear stress on plateletderived growth factor isoform release by endothelial cells-consequences for smooth muscle cell migration. Arteriosclerosis Thrombosis Vasc Biol 2002;22: 405-411.

44 Morita T, Yoshizumi M, Kurihara H, et al. Shear-stress increases heparin-binding epidermal growth factorkike growth-factor messenger-RNA levels in human vascular endothelial-cells. Biochem Biophys Res Commun 1993;197:256-262.

45 Gloe T, Sohn HY, Meininger GA, et al. Shear stressinduced release of basic fibroblast growth factor from endothelial cells is mediated by matrix interaction via integrin alpha(V)beta(3). J Biol Chem 2002;277: 23453-23458.

46 Hagiwara H, Mitsumata M, Yamane T, et al. Laminar shear stress-induced GRO mRNA and protein expression in endothelial cells. Circulation 1998;98: 2584-2590.

47 Kosaki K, Ando J, Korenaga R, et al. Fluid shear stress increases the production of granulocyte-macrophage colony-stimulating factor by endothelial cells via mRNA stabilization. Circ Res 1998;82:794-802.

48 Takada Y, Shinkai F, Kondo S, et al. Fluid shear-stress increases the expression of thrombomodulin by cultured human endothelial-cells. Biochem Biophys Res Commun 1994;205:1345-1352.

49 Lin MC, AlmusJacobs F, Chen HH, et al. Shear stress induction of the tissue factor gene. J Clin Invest 1997;99:737-744.

50 Diamond SL, Eskin SG, Mcintire LV. Fluid-flow stimulates tissue plasminogen-activator secretion by cultured human-endothelial cells. Science 1989;243: 1483-1485.

51 Nguyen KT, Eskin SG, Patterson C, et al. Sheer stress reduces protease activated receptor- 1 expression in human endothelial cells. Ann Biomed Eng 2001;29: 145-152.

52 Bongrazio M, Pries AR, Zakrzewicz A. The endothelium as physiological source of properdin: role of wall shear stress. Mol Immunol 2003;39:669-675.

53 Jin X, Iwasa S, Okada K, et al. Shear stress-induced collagen XII expression is associated with atherogenesis. Biochem Biophys Res Commun 2003;308: 152-158.

54 Magid R, Murphy TJ, Galis ZS. Expression of matrix metalloproteinase-9 in endothelial cells is differentially regulated by shear stress-role of c-Myc. J Biol Chem 2003;278:32994-32999.

55 Elhadj S, Akers RM, Forsten-Williams K. Chronic pulsatile shear stress alters insulin-like growth factorI (IGF-I) binding protein release in vitro. Ann Biomed Eng 2003;31:163-170.
56 Ohno M, Gibbons GH, Dzau VJ, et al. Shear-stress elevates endothelial Cgmp-role of a potassium channel and G-protein coupling. Circulation 1993;88: 193-197.

57 Passerini AG, Milsted A, Rittgers SE. Shear stress magnitude and directionality modulate growth factor gene expression in preconditioned vascular endothelial cells. J Vasc Surg 2003;37:182-190.

58 Dai G, Kaazempur-Mofrad MR, Natarajan S, et al. Distinct endothelial phenotypes evoked by arterial waveforms derived from atherosclerosis-susceptible and -resistant regions of human vasculature. Proc Nat Acad Sci USA 2004;101:14871-14876.

59 Hajra L, Evans AI, Chen M, et al. The NF-kappa B signal transduction pathway in aortic endothelial cells is primed for activation in regions predisposed to atherosclerotic lesion formation. Proc Natl Acad Sci USA 2000;97:9052-9057.

60 Nagel T, Resnick N, Dewey CF, et al. Vascular endothelial cells respond to spatial gradients in fluid shear stress by enhanced activation of transcription factors. Arteriosclerosis Thrombosis Vasc Biol 1999;19: 1825-1834

61 Brooks AR, Lelkes PI, Rubanyi GM. Gene expression profiling of vascular endothelial cells exposed to fluid mechanical forces: Relevance for focal susceptibility to atherosclerosis. Endothelium-J Endothelial Cell Res 2004;11:45-57.

62 Seo D, Karra R, Wang T, et al. Genomic convergence in the study of human and mouse atherosclerosis. Circulation 2003;108:282.

63 Dancu M, Berardi D, Vanden Heuvel J, et al. The effects of pathologic hemodynamics on vasoactive gene expression in endothelial cells. FASEB J 2004;18: A954.

64 Chen XL, Varner SE, Rao AS, et al. Laminar flow induction of antioxidant response element-mediated genes in endothelial cells-a novel anti-inflammatory mechanism. J Biol Chem 2003;278:703-711.

65 Liu Y, Zhu Y, Rannou F, et al. Laminar flow activates peroxisome proliferator-activated receptor-gamma in vascular endothelial cells. Circulation 2004;110: 1128-1133.

66 Ni CW, Hsieh HJ, Chao YJ, et al. Shear flow attenuates serum-induced STAT3 activation in endothelial cells. J Biol Chem 2003;278:19702-19708.

67 Chiu JJ, Lee PL, Chen CN, et al. Shear stress increases ICAM-1 and decreases VCAM-1 and E-selectin expressions induced by tumor necrosis factor-alpha in endothelial cells. Arteriosclerosis Thrombosis Vasc Biol 2004;24:73-79.

68 Walpola PL, Gotlieb AI, Cybulsky MI, et al. Expression of Icam-1 and Vcam-1 and monocyte adherence in arteries exposed to altered shear-stress. Arteriosclerosis Thrombosis Vasc Biol 1995;15:2-10.

69 Hsiai TK, Cho SK, Wong PK, et al. Monocyte recruitment to endothelial cells in response to oscillatory shear stress. FASEB J 2003;17:1648-1657.

70 Chappell DC, Varner SE, Nerem RM, et al. Oscillatory shear stress stimulates adhesion molecule expression in cultured human endothelium. Circulation Res 1998;82:532-539.

71 Sheikh S, Rainger GE, Gale Z, et al. Exposure to fluid shear stress modulates the ability of endothelial cells to recruit neutrophils in response to tumor 
necrosis factor-alpha: a basis for local variations in vascular sensitivity to inflammation. Blood 2003;102: 2828-2834.

72 Yamawaki H, Lehoux S, Berk BC. Chronic physiological shear stress inhibits tumor necrosis factorinduced proinflammatory responses in rabbit aorta perfused ex vivo. Circulation 2003;108:1619-1625.

73 Chiu JJ, Chen LJ, Lee PL, et al. Shear stress inhibits adhesion molecule expression in vascular endothelial cells induced by coculture with smooth muscle cells. Blood 2003;101:2667-2674.

74 Sorescu GP, Sykes M, Weiss D, et al. Bone morphogenic protein 4 produced in endothelial cells by oscillatory shear stress stimulates an inflammatory response. J Biol Chem 2003;278:31128-31135.

75 Heeneman S, Cleutjens JP, Faber BC, et al. The dynamic extracellular matrix: intervention strategies during heart failure and atherosclerosis. J Pathol 2003;200:516-525.

76 Mohler ER, Gannon F, Reynolds C, et al. Bone formation and inflammation in cardiac valves. Circulation 2001;103:1522-1528.

77 Rubanyi GM, Romero JC, Vanhoutte PM. Flowinduced release of endothelium-derived relaxing factor. Am J Physiol 1986;250:1145-1149.

78 Awolesi MA, Widmann MD, Sessa WC, et al. Cyclic strain increases endothelial nitric-oxide synthase activity. Surgery 1994;116:439-445.

79 Li JR, Billiar TR, Talanian RV, et al. Nitric oxide reversibly inhibits seven members of the caspase family via S-nitrosylation. Biochem Biophys Res Commun 1997;240:419-424.

80 Freedman JE, Sauter R, Battinelli EM, et al. Deficient platelet-derived nitric oxide and enhanced hemostasis in mice lacking the NOSIII gene. Circ Res 1999;84:1416-1421.

81 Tsao PS, Buitrago R, Chan JR, et al. Fluid flow inhibits endothelial adhesiveness-nitric oxide and transcriptional regulation of VCAM-1. Circulation 1996;94: 1682-1689.

82 Dimmeler S, Hermann C, Galle J, et al. Upregulation of superoxide dismutase and nitric oxide synthase mediates the apoptosis-suppressive effects of shear stress on endothelial cells. Arteriosclerosis Thrombosis Vasc Biol 1999;19:656-664.

83 Kuhlencordt PJ, Rosel E, Gerszten RE, et al. Role of endothelial nitric oxide synthase in endothelial activation: insights from eNOS knockout endothelial cells. Am J Physiol-Cell Physiol 2004;286:C1195C1202.

84 Casas JP, Bautista LE, Humphries SE, et al. Endothelial nitric oxide synthase genotype and ischemic heart disease: meta-analysis of 26 studies involving 23028 subjects. Circulation 2004;109:1359-1365.

85 Feron O, Smith TW, Michel T, et al. Dynamic targeting of the agonist-stimulated $\mathrm{m} 2$ muscarinic acetylcholine receptor to caveolae in cardiac myocytes. J Biol Chem 1997;272:17744-17748.

86 Cai H, Li ZM, Davis ME, et al. Akt-dependent phosphorylation of serine 1179 and mitogen-activated protein kinase kinase/extracellular signal-regulated kinase 1/2 cooperatively mediate activation of the endo-

thelial nitric-oxide synthase by hydrogen peroxide. Mol Pharmacol 2003;63:325-331.

87 Hisamoto K, Ohmichi M, Kurachi H, et al. Estrogen induces the Akt-dependent activation of endothelial nitric-oxide synthase in vascular endothelial cells. J Biol Chem 2001;276:3459-3467.

88 Bernier SG, Michel T. Dynamic regulation of caveolae-targeted signaling proteins by bradykinin: endothelial nitric-oxide synthase forms a reversible complex with Raf-1/map kinase/kinase AKT. FASEB J 2000;14:A1375.

89 Morales-Ruiz M, Lee MJ, Zollner S, et al. Sphingosine 1-phosphate activates Akt, nitric oxide production, and chemotaxis through a G(i) protein/phosphoinositide 3-kinase pathway in endothelial cells. J Biol Chem 2001;276:19672-19677.

90 Papapetropoulos A, Garcia-Cardena G, Madri JA, et al. Nitric oxide production contributes to the angiogenic properties of vascular endothelial growth factor in human endothelial cells. J Clin Invest 1997;100: 3131-3139.

91 Alonso J, deMiguel LS, Monton M, et al. Endothelial cytosolic proteins bind to the $3^{\prime}$ untranslated region of endothelial nitric oxide synthase mRNA: regulation by tumor necrosis factor alpha. Mol Cell Biol 1997;17: 5719-5726.

92 Sessa WC, Pritchard K, Seyedi N, et al. Chronic exercise in dogs increases coronary vascular nitricoxide production and endothelial-cell nitric-oxide synthase gene-expression. Circ Res 1994;74: 349-353.

93 Wilcox JN, Subramanian RR, Sundell CL, et al. Expression of multiple isoforms of nitric oxide synthase in normal and atherosclerotic vessels. Arteriosclerosis Thrombosis Vasc Biol 1997;17: 2479-2488.

94 Bossaller C, Habib GB, Yamamoto H, et al. Impaired muscarinic endothelium-dependent relaxation and cyclic guanosine $5^{\prime}$-monophosphate formation in atherosclerotic human coronary-artery and rabbit aorta. J Clin Invest 1987;79:170-174.

95 Davis ME, Cai H, Drummond GR, et al. Shear stress regulates endothelial nitric oxide synthase expression through c-Src by divergent signaling pathways. Circ Res 2001;89:1073-1080.

96 Peng HB, Libby P, Liao JK. Induction and stabilization of I-kappa-B-alpha by nitric-oxide mediates inhibition of Nf-kappa-B. J Biol Chem 1995;270:1421414219.

$97 \mathrm{Ju} \mathrm{H}$, Zou R, Venema VJ, et al. Direct interaction of endothelial nitric-oxide synthase and caveolin-1 inhibits synthase activity. J Biol Chem 1997;272: 18522-18525.

98 Fleming I, Busse R. Molecular mechanisms involved in the regulation of the endothelial nitric oxide synthase. Am J Physiol-Regul Integrative Comp Physiol 2003;284:R1-R12.

99 Cho HJ, Xie QW, Calaycay J, et al. Calmodulin is a subunit of nitric-oxide synthase from macrophages. J Exp Med 1992;176:599-604.

100 Brouet A, Sonveaux P, Dessy C, et al. Hsp90 ensures the transition from the early $\mathrm{Ca}^{2+}$-dependent to the late phosphorylation-dependent activation of the endothelial nitric-oxide synthase in vascular endothelial growth factor-exposed endothelial cells. J Biol Chem 2001;276:32663-32669.

101 Cao S, Yao J, Mccabe TJ, et al. Direct interaction between endothelial nitric-oxide synthase and dynamin-2-implications for nitric-oxide synthase function. J Biol Chem 2001;276:14249-14256. 
102 Sun JX, Liao JK. Functional interaction of endothelial nitric oxide synthase with a voltage-dependent anion channel. Proc Natl Acad Sci USA 2002;99: 13108-13113.

103 Venema RC, Venema VJ, Ju H, et al. Novel complexes of guanylate cyclase with heat shock protein 90 and nitric oxide synthase. Am J Physiol-Heart Circ Physiol 2003;285:H669-H678.

104 Marrero MB, Venema VJ, Ju H, et al. Endothelial nitric oxide synthase interactions with G-protein-coupled receptors. Biochem J 1999;343:335-340.

105 Dedio J, Konig P, Wohlfart P, et al. NOSIP, a novel modulator of endothelial nitric oxide synthase activity. FASEB J 2001;15:79-89.

106 Dusserre N, L'Heureux N, Bell KS, et al. PECAM-1 interacts with nitric oxide synthase in human endothelial cells. Implication for flow-induced nitric oxide synthase activation. Arteriosclerosis Thrombosis Vasc Biol 2004; Epub ahead of print.

107 Kaufman DA, Albelda SM, Sun J, et al. Role of lateral cell-cell border location and extracellular/transmembrane domains in PECAM/CD31 mechanosensation. Biochem Biophys Res Commun 2004;320:1076-1081.

108 Boo YC, Sorescu GP, Bauer PM, et al. Endothelial NO synthase phosphorylated at Ser(635) produces no without requiring intracellular calcium increase. Free Radical Biol Med 2003;35:729-741.

109 Boo YC, Jo H. Flow-dependent regulation of endothelial nitric oxide synthase: role of protein kinases. Am J Physiol-Cell Physiol 2003;285:C499-C508.

110 Chen ZP, Mitchelhill KI, Michell BJ, et al. AMPactivated protein kinase phosphorylation of endothelial NO synthase. FEBS Lett 1999;443:285-289.

111 Lin MI, Fulton D, Babbitt R, et al. Phosphorylation of threonine 497 in endothelial nitric-oxide synthase coordinates the coupling of L-arginine metabolism to efficient nitric oxide production. J Biol Chem 2003; 278:44719-44726.

112 Boo YC, Sorescu G, Boyd N, et al. Shear stress stimulates phosphorylation of endothelial nitricoxide synthase at Ser(1179) by Akt-independent mechanisms-role of protein kinase A. J Biol Chem 2002;277:3388-3396.

113 Dimmeler S, Fleming I, Fisslthaler B, et al. Activation of nitric oxide synthase in endothelial cells by Aktdependent phosphorylation. Nature 1999;399:601605.

114 Butt E, Bernhardt M, Smolenski A, et al. Endothelial nitric-oxide synthase (type III) is activated and becomes calcium independent upon phosphorylation by cyclic nucleotide-dependent protein kinases. J Biol Chem 2000;275:5179-5187.

115 Fleming I, Fisslthaler B, Dimmeler S, et al. Phosphorylation of $\mathrm{Thr}(495)$ regulates $\mathrm{Ca}^{2+} /$ calmodulin-dependent endothelial nitric oxide synthase activity. Circ Res 2001;88:E68-E75.

116 Heijnen HF, Waaijenborg S, Crapo JD, et al. Colocalization of eNOS and the catalytic subunit of PKA in endothelial cell junctions: a clue for regulated NO production. J Histochem Cytochem 2004;52: 1277-1285.

117 Jin ZG, Ueba H, Tanimoto T, et al. Ligand-independent activation of vascular endothelial growth factor receptor 2 by fluid shear stress regulates activation of endothelial nitric oxide synthase. Circ Res 2003;93:354-363.
118 Davis ME, Cai H, McCann L, et al. Role of c-Src in regulation of endothelial nitric oxide synthase expression during exercise training. Am J PhysiolHeart Circ Physiol 2003;284:H1449-H1453.

119 Hambrecht R, Adams V, Erbs S, et al. Regular physical activity improves endothelial function in patients with coronary artery disease by increasing phosphorylation of endothelial nitric oxide synthase. Circulation 2003;107:3152-3158.

120 Hoffmann J, Dimmeler S, Haendeler J. Shear stress increases the amount of $S$-nitrosylated molecules in endothelial cells: important role for signal transduction. FEBS Lett 2003;551:153-158.

121 Martin S, Tesse A, Hugel B, et al. Shed membrane particles from $\mathrm{T}$ lymphocytes impair endothelial function and regulate endothelial protein expression. Circulation 2004;109:1653-1659.

122 Cattaruzza M, Guzik TJ, Slodowski W, et al. Shear stress insensitivity of endothelial nitric oxide synthase expression as a genetic risk factor for coronary heart disease. Circ Res 2004;95:841-847.

123 Lassegue B, Clempus RE. Vascular NAD(P)H oxidases: specific features, expression, and regulation. Am J Physiol-Regul Integrative Comp Physiol 2003; 285:R277-R297.

124 Rodriguez C, Raposo B, Martinez-Gonzalez J, et al. Low density lipoproteins downregulate lysyl oxidase in vascular endothelial cells and the arterial wall. Arteriosclerosis Thrombosis Vasc Biol 2002;22: 1409-1414.

125 McNally JS, Davis ME, Giddens DP, et al. Role of xanthine oxidoreductase and $\mathrm{NAD}(\mathrm{P}) \mathrm{H}$ oxidase in endothelial superoxide production in response to oscillatory shear stress. Am J Physiol-Heart Circ Physiol 2003;285:H2290-H2297.

126 Cathcart MK. Regulation of superoxide anion production by NADPH oxidase in monocytes/ macrophages-contributions to atherosclerosis. Arteriosclerosis Thrombosis Vasc Biol 2004;24:23-28.

127 Vasquez-Vivar J, Kalyanaraman B, Martasek P, et al. Superoxide generation by endothelial nitric oxide synthase: The influence of cofactors. Proc Natl Acad Sci USA 1998;95:9220-9225.

128 Rajagopalan S, Kurz S, Munzel T, et al. Angiotensin II-mediated hypertension in the rat increases vascular superoxide production via membrane NADH/NADPH oxidase activation-contribution to alterations of vasomotor tone. J Clin Investig 1996;97:1916-1923.

129 Hwang J, Saha A, Boo YC, et al. Oscillatory shear stress stimulates endothelial production of O2- from p47(phox)-dependent NAD(P)H oxidases, leading to monocyte adhesion. J Biol Chem 2003;278: 47291-47298.

130 Harrison D, Griendling KK, Landmesser U, et al. Role of oxidative stress in atherosclerosis. Am J Cardiol 2003;91:7A-11A.

131 Touyz RM, Schiffrin EL. Ang II-stimulated generation of vascular smooth muscle cell reactive oxygen species is increased in human hypertension: role of phospholipase D. Circulation 1999;100:479.

132 De Keulenaer GW, Chappell DC, Ishizaka N, et al. Oscillatory and steady laminar shear stress differentially affect human endothelial redox state-role of a superoxide-producing NADH oxidase. Circ Res 1998;82:1094-1101.

133 Hwang J, Ing MH, Salazar A, et al. Pulsatile versus oscillatory shear stress regulates $\mathrm{NADPH}$ oxidase 
subunit expression-implication for native LDL oxidation. Circ Res 2003;93:1225-1232.

134 Fukuda Y, Teragawa H, Matsuda K, et al. Tetrahydrobiopterin restores endothelial function of coronary arteries in patients with hypercholesterolaemia. Heart 2002;87:264-269.

135 Nystrom T, Nygren A, Sjoholm A. Tetrahydrobiopterin increases insulin sensitivity in patients with type 2 diabetes and coronary heart disease. Am J PhysiolEndocrinol Metab 2004;July:20.

136 Hong HJ, Hsiao G, Cheng TH, et al. Supplemention with tetrahydrobiopterin suppresses the development of hypertension in spontaneously hypertensive rats. Hypertension 2001;38:1044-1048.

137 Hermann C, Zeiher AM, Dimmeler S. Shear stress induced up-regulation of superoxide dismutase inhibits tumor necrosis factor alpha-mediated apoptosis of endothelial cells. Circulation 1997;96:2732.

138 Takeshita S, Inoue N, Ueyama T, et al. Shear stress enhances glutathione peroxidase expression in endothelial cells. Biochem Biophys Res Commun 2000; 273:66-71.

139 Faraci FM, Didion SP. Vascular protection-superoxide dismutase isoforms in the vessel wall. Arteriosclerosis Thrombosis Vasc Biol 2004;24:1367-1373.

140 Sun D, Huang A, Yan EH, et al. Reduced release of nitric oxide to shear stress in mesenteric arteries of aged rats. Am J Physiol-Heart Circ Physiol 2004;286: H2249-H2256.

141 Woodman CR, Muller JM, Rush JWE, et al. Flow regulation of ecNOS and $\mathrm{Cu} / \mathrm{Zn}$ SOD mRNA expression in porcine coronary arterioles. Am J PhysiolHeart Circ Physiol 1999;276:H1058-H1063.

142 Horiuchi M, Tsutsui M, Tasaki H, et al. Upregulation of vascular extracellular superoxide dismutase in patients with acute coronary syndromes. Arteriosclerosis Thrombosis Vasc Biol 2004;24:106-111.

143 Jaimes EA, DeMaster EG, Tian RX, et al. Stable compounds of cigarette smoke induce endothelial superoxide anion production via NADPH oxidase activation. Arteriosclerosis Thrombosis Vasc Biol 2004;24:1031-1036.

144 Ungvari Z, Csiszar A, Kaminski PM, et al. Chronic high pressure-induced arterial oxidative stressinvolvement of protein kinase C-dependent NAD(P)H oxidase and local renin-angiotensin system. Am J Pathol 2004;165:219-226.

145 Gross ER, Ladisa JF, Weihrauch D, et al. Reactive oxygen species modulate coronary wall shear stress and endothelial function during hyperglycemia. Am J Physiol-Heart Circ Physiol 2003;284:H1552-H1559.

146 Stokes KY, Clanton EC, Russell JM, et al. NAD(P)H oxidase-derived superoxide mediates hypercholesterolemia-induced leukocyte-endothelial cell adhesion. Circ Res 2001;88:499-505.

147 Warnholtz A, Nickenig G, Schulz E, et al. Increased NADH-oxidase-mediated superoxide production in the early stages of atherosclerosis-evidence for involvement of the renin-angiotensin system. Circulation 1999;99:2027-2033.

148 Pizzi C, Manfrini O, Fontana F, et al. Angiotensinconverting enzyme inhibitors and 3-hydroxy-3methylglutaryl coenzyme A reductase in cardiac syndrome $\mathrm{X}$-role of superoxide dismutase activity. Circulation 2004;109:53-58.

149 Wagner AH, Kohler T, Ruckschloss U, et al. Improvement of nitric oxide-dependent vasodilatation by
HMG-CoA reductase inhibitors through attenuation of endothelial superoxide anion formation. Arteriosclerosis Thrombosis Vasc Biol 2000;20:61-69.

150 de Nigris F, Lerman A, Ignarro LJ, et al. Oxidationsensitive mechanisms, vascular apoptosis and atherosclerosis. Trends Mol Med 2003;9:351-359.

151 Micheletta F, Natoli S, Misuraca M, et al. Vitamin E supplementation in patients with carotid atherosclerosis-reversal of altered oxidative stress status in plasma but not in plaque. Arteriosclerosis Thrombosis Vasc Biol 2004;24:136-140.

152 Khatri JJ, Johnson C, Magid R, et al. Vascular oxidant stress enhances progression and angiogenesis of experimental atheroma. Circulation 2004;109: $520-525$

153 Weinberg PD. Rate-limiting steps in the development of atherosclerosis: the response-to-influx theory. J Vasc Res 2004;41:1-17.

154 VanderLaan PA, Reardon CA, Getz GS. Site specificity of atherosclerosis-site-selective responses to atherosclerotic modulators. Arteriosclerosis Thrombosis Vasc Biol 2004;24:12-22.

155 Lin SJ, Jan KM, Schuessler G, et al. Enhanced macromolecular permeability of aortic endothelialcells in association with mitosis. Atherosclerosis 1988;73:223-232.

156 Himburg HA, Grzybowski DM, Hazel AL, et al. Spatial comparison between wall shear stress measures and porcine arterial endothelial permeability. Am J Physiol-Heart Circ Physiol 2004;286: H1916-H1922.

157 Kim DW, Langille BL, Wong MKK, et al. Patterns of endothelial microfilament distribution in the rabbit aorta in situ. Circ Res 1989;64:21-31.

158 Lee TYJ, Gotlieb AI. Microfilaments and microtubules maintain endothelial integrity. Microsc Res Tech 2003;60:115-125.

159 Vyalov S, Langille BL, Gotlieb AI. Decreased blood flow rate disrupts endothelial repair in vivo. Am J Pathol 1996;149:2107-2118.

160 Colangelo S, Langille BL, Gotlieb AI. Patterns of distribution characterize the organization of endothelial microfilaments at aortic flow dividers. Cell Tissue Res 1994;278:235-242.

161 Wong MKK, Gotlieb AI. Endothelial-cell monolayer integrity. 1. Characterization of dense peripheral band of microfilaments. Arteriosclerosis 1986;6:212-219.

162 Wong MKK, Gotlieb AI. The role of the dense peripheral band of microfilaments in the maintenance of endothelial integrity. J Cell Biol 1983;97: A267.

163 Lee JSY, Gotlieb AI. Microtubule-actin interactions may regulate endothelial integrity and repair. Cardiovasc Pathol 2002;11:135-140.

164 Noria S, Cowan DB, Gotlieb AI, et al. Transient and steady-state effects of shear stress on endothelial cell adherens junctions. Circ Res 1999;85:504-514.

165 Langille BL, Graham JJK, Kim D, et al. Dynamics of shear-induced redistribution of F-actin in endothelial-cells in vivo. Arteriosclerosis Thrombosis 1991;11: 1814-1820.

166 Noria S, Xu F, Mccue S, et al. Assembly and reorientation of stress fibers drives morphological changes to endothelial cells exposed to shear stress. Am J Pathol 2004;164:1211-1223. 
167 Barbee KA, Mundel T, Lal R, et al. Distribution of shear-stress on the surface of aligned and un-aligned endothelial monolayers. Hypertension 1994;24:384.

168 Jo H, Dull RO, Hollis TM, et al. Endothelial albumin permeability is shear dependent, time-dependent, and reversible. Am J Physiol 1991;260:H1992-H1996.

169 Dickson BC, Gotlieb AI. Endothelial dysfunction and repair in the pathogenesis of stable and unstable fibroinflammatory atheromas. Can J Cardiol 2004;20: 16B-23B.

170 Colangelo S, Langille BL, Steiner G, et al. Alterations in endothelial $\mathrm{F}$-actin microfilaments in rabbit aorta in hypercholesterolemia. Arteriosclerosis Thrombosis Vasc Biol 1998;18:52-56.

171 Lin T, Seng L, Liu Y, et al. Rho-ROCK-CIMK-Cofilin pathway regulates shear stress activation of sterol regulatory element binding proteins. Circ Res 2003;92:1296-1304.

172 Cooley BC. Murine model of neointimal formation and stenosis in vein grafts. Arteriosclerosis Thrombosis Vasc Biol 2004;24:1180-1185.

173 Butany JW, David TE, Ojha M. Histological and morphometric analyses of early and late aortocoron- ary vein grafts and distal anastomoses. Can J Cardiol 1998;14:671-677.

174 Wentzel JJ, Krams R, Schuurbiers JCH, et al. Relationship between neointimal thickness and shear stress after wallstent implantation in human coronary arteries. Circulation 2001;103:1740-1745.

175 Kinlay S, Grewal J, Manuelin D, et al. Coronary flow velocity and disturbed flow predict adverse clinical outcome after coronary angioplasty. Arteriosclerosis Thrombosis Vasc Biol 2002;22:1334-1340.

176 Welt FGP, Rogers C. Inflammation and restenosis in the stent era. Arteriosclerosis Thrombosis Vasc Biol 2002;22:1769-1776.

177 Ladisa JF, Olson LE, Guler I, et al. Stent design properties and deployment ratio influence indexes of wall shear stress: a three-dimensional computational fluid dynamics investigation within a normal artery. J Appl Physiol 2004;97:424-430.

178 Hoffmann R, Mintz GS, Dussaillant GR, et al. Patterns and mechanisms of in-stent restenosis-a serial intravascular ultrasound study. Circulation 1996;94:1247-1254. 